tube is removed, thus giving passage to the beam from the rear mirror. The principle is therefore that of the Donnan colorimeter. The form and dimensions of the silver surface removed will be a matter of personal choice. I have tried many different forms. and prefer to use the instrument as a half-shade apparatus, diaphragming the field to about 5 or $6 \mathrm{~mm}$. diameter. When desirable a light filter is used to increase the delicacy of observation.

Measurements are made by comparing the solution in question with some standard. The millimeter scale and vernier are used when the height of the liquid column is several centimeters. To permit accurate comparisons with solutions only a few millimeters in height a simple micrometer, reading $0.01 \mathrm{~mm}$., has been devised. This attachment is thrown into service by a pivot and can be released when not needed.

A high degree of accuracy can be attained if the eye has been trained to make color comparisons for several weeks. In working with various copper- and nickel-ammonia complexes I have tépeatedly checked observations to o.I $\mathrm{mm}$. The micrometer attachment has been devised only recently and consequently I am not yet in a position to state the ultimate delicacy of the observations recorded with this instrument.

The apparatus has a compact form, as is evident from the diagram. It is, moreover, inexpensive. As a substitute for the etched scale on the brass tube a paper scale such as is provided with galvanometers might be used. It is necessary, of course, to calibrate both the millimeter scale and the micrometer. For very accurate measurements a zero reading is made with each determination by lowering the float cylinder until the two glass plates are in contact, the scale having such a range that this zero reading is always positive.

ANN ARBOR, June 18, 1906.

\title{
ANTIMONY IN BABBITT AND TYPE METALS.
}

BY H. YOCKEY.

Received July 23, I906.

IN the May number of this Journal a paper by the author of this article appeared describing the analysis of Babbitt metal as practiced in this laboratory. Antimony was described as being determined by the method of Walters and Apfelder. Since appearing, a number of objections to this method have been received 
by me and from such well-known chemists that I could not ignore them, so I determined to try to better the method if I could. The following method is the result of these experiments. By this method antimony can be determined accurately in alloys containing tin and antimony; lead and antimony; lead, tin and antimony; tin, copper and antimony; lead, tin, copper and antimony; and lead, copper and antimony. In these alloys the copper never exceeded 7 per cent. What would be the results with a high copper content, I have not determined.

Treat I gram filings with I gram potassium iodide, $40 \mathrm{cc}$, water and $40 \mathrm{cc}$. concentrated hydrochloric acid (sp. gr. I.2), and boil gently one hour. Filter on asbestos in a Gooch crucible, washing five or six times with hot dilute hydrochloric acid ( $\mathrm{I}: \mathrm{IO}$ ).

Wash the precipitate and asbestos into a $150 \mathrm{cc}$. beaker with a little wash-water, and add 20 or $25 \mathrm{cc}$. concentrated hydrochloric acid and a few crystals of potassium chlorate. Cover with a watch-glass and warm gently, stirring occasionally.

When the antimony is in solution dilute to roo $\mathrm{cc}$. and filter the asbestos out, washing until the wash-water shows no hydrochloric acid. Boil vigorously five minutes to free the solution from free chlorine. Cool to room temperature, add I gram of potassium iodide in solution and titrate the liberated iodine with a standard thiosulphate solution.

The following results were obtained by this method. The alloys were all made from new commercially pure metals by myself.

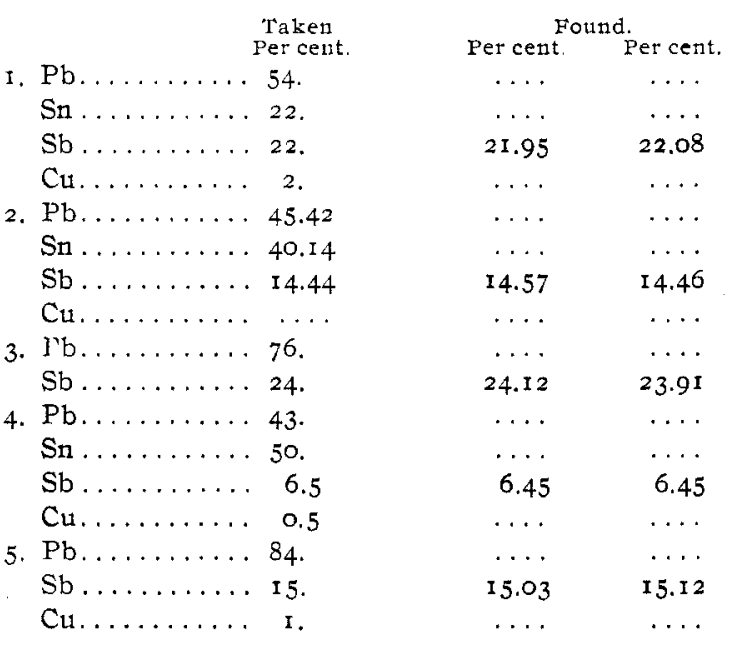


The last example I give is the result on an alloy sent me by the Pittsburg Section of the American Chemical Society for analysis. The alloy contained, as reported to me after I had sent in my report, the following: 4.98 to 5.02 per cent. copper, 14.70 per cent. antimony, and the balance tin. My report by this method was I4.73 per cent. antimony, the average of two determinations.

National LEAD Co.,

Cincinnati Branch.

\section{THE ETCHING TEST FOR SMALL AMOUNTS OF FLUORIDES.}

BY A, G. WOODMaN AND H. P. TALBOT.

Received July 3I, Iģo6.

IN THE course of some work on the detection of fluorides in malt liquors it was found necessary to make a study of the etching test on glass as commonly employed, both from its stand point as a qualitative test and with a view to making it approximately quantitative.

As a qualitative test, the etching method was found eminently satisfactory, as regards delicacy and reliability, if carried out under proper conditions. The procedure employed was the same in principle as that proposed by Blarez, ${ }^{1}$ later modified by Leach, ${ }^{2}$ and adopted as a provisional method by the Association of Official Agricultural Chemists. ${ }^{3}$ It may be described briefly as follows: To I $50 \mathrm{cc}$. of the liquid to be tested add ro cc. of potassium sulphate ( 33 grams per liter), heat the solution to boiling and while boiling add slowly from a burette or pipette Io cc. of a Io per cent. barium acetate solution. Continue the boiling for a moment and then set the beaker aside for the precipitated barium sulphate and fluoride to settle. In most cases, unless the precipitate settles very readily, it is preferable to let it stand over night. The clear supernatant liquid is decanted, the precipitate transferred to a filter, washed and ignited in a platinum crucible. An alternative method which is more rapid and has the added advantage of avoiding the use of filters, is to decant off the clear liquid and wash the precipitate into one of the tubes of a centrifugal machine. The sedimented material is then washed directly into a platinum

1 Chem. News, 9r, 39 (1905).

2 Ann. Rept. Mass. State Board Health, I905.

3 U. S. Dept. Agr., Bur. Chem., Circular 28. 